\title{
Effects of Salt Concentration on Osmotic Dehydration of Green Bean
}

\author{
Aluízio Freire da Silva Júnior, Juarez Everton de Farias Aires, Kalina Lígia C. A. Farias Aires \\ Cleide Maria Diniz Pereira da Silva e Silva, Vera Solange de O. Farias \\ Federal University of Campina Grande, Paraiba, Brazil
}

Wilton Pereira da Silva (Corresponding author)

Federal University of Campina Grande, Paraiba, Brazil

Tel: 55-83-3099-0759Ｅ-mail: wiltonps@uol.com.br

\author{
Received: December 27, 2014 Accepted: January 12, 2015 \\ doi:10.5296/jas.v3i1.6833ＵRL: http://dx.doi.org/10.5296/jas.v3i1.6833
}

\begin{abstract}
In this study, mass transfer simulations were performed during the process of osmotic dehydration of green beans in $\mathrm{NaCl}$ solutions of 20 and $26.5 \%$ at $50{ }^{\circ} \mathrm{C}$. Additionally, the effect of solute concentration on boundary conditions was investigated. For such, a diffusion model assuming constant diffusivity - and the geometry of an infinite cylinder was considered. A numerical solution was also developed and coupled with an optimizer in order to obtain the process parameters using experimental data. The results were consistent with those mentioned in the literature, for which analytical tools were utilized to describe the process.
\end{abstract}

Keywords: Osmotic dehydration, Mass Transfer, Diffusivity, Convective transfer coefficient

\section{Introduction}

Osmotic dehydration is a process through which water is removed from fruits and vegetables by dipping them in a hypertonic solution. During this process, occurs water migration from the product to the solution and solid migration from the solution to the product. These migrations have been studied in various fruits and vegetables (Fathi et al., 2011; Mercali et al, 2011; Sutar et al., 2012; Porciuncula et al., 2013; Silva et al., 2014). However, with respect to the green bean, few works on osmotic dehydration and convective drying are found in the literature, despite its importance as a product consumed in most countries worldwide. Souraki et al. (2012) studied the process of osmotic dehydration of green beans in solutions of $\mathrm{NaCl}$, and used the standard model suggested by Azuara et al. (1992) in order to describe the kinetics of the 
osmotic process. In another study in which green bean was used, Souraki et al. (2013) employed an interpolating polynomial in order to obtain an approximate solution to the diffusion equation, and then simulated the mass transfers of the osmotic dehydration process. It has also been observed that the model obtained by the interpolating polynomial, when compared with the exact solution, overestimates the results in some stages of the process and underestimates the results at other stages. This observation points towards the need for further studies. In another study, Doymaz (2005) conducted experiments on convective drying of green beans in order to study the effect of temperature on the kinetics of the drying process. To describe this process, empirical equations were used. Other authors have used similar approaches to describe convective drying of fruits and vegetables (Kaleta and Górnicki, 2010; Doymaz and Ismail, 2011; Fante et al., 2011; Silva et al., 2013a).

A common approach to problems of dehydration is the use of analytical solutions in diffusion models in order to describe the two mass transfers found in the process (Falade et al., 2007, Ruiz-Lopez et al., 2010; Uribe et al., 2011). Silva et al. (2013b) employed an analytical solution from the diffusion equation with infinite slab geometry to describe mass migration in coconut slices during the process of convective drying and osmotic dehydration. However, analytical solutions have some limitations. For instance, they do not take into account the variation of physical parameters, nor the material shrinkage along the process. Consequently, one of the advantages of using numerical tools rests mainly upon the fact that physical parameters may vary in time and space, and also upon the fact that one may still consider the shrinkage phenomenon, which is physically more appropriate. In order to implement a better description of mass flow resistance on the surface of the product, some studies on diffusion have considered the boundary condition of the third kind, which permits one to obtain parameters such as the convective mass transfer coefficient. Silva et al. (2013c) have considered the condition of the third kind for the three-dimensional diffusion equation in order to provide a detailed description of the removal of water from coconuts cut up in rectangular slices, along a process of osmotic dehydration followed by convective drying. An analytical solution was used for the three-dimensional diffusion equation coupled with an optimizer in order to determine physical parameters. Despite its importance, there are few studies in the literature using this boundary condition in their analysis (Silva et al., 2010; Silva et al., 2013d.). Nevertheless, in the case of osmotic dehydration, depending on the process conditions such as agitation and concentration of solution, a boundary condition of the first kind may be used to describe the process (Mercali et al., 2011).

The main objective of this work is to describe the osmotic dehydration of green beans through the numerical solution of the one-dimensional diffusion equation, using cylindrical coordinates. In the numerical solution, was used the finite volume method, with a fully implicit formulation. The appropriate boundary condition for each mass flow was analyzed, considering the effective diffusivity of water and solids as a constant parameter. For this matter, an optimizer was coupled with the numerical solution in order to determine the optimum process parameters via inverse method, using experimental data. Lastly, the distributions of water and solids within the product was presented at some moments of the osmotic dehydration process. 


\section{Macrothink}

\section{Material and Methods}

\subsection{Mathematical Modeling}

In the present work, diffusion models are used to describe mass transfer in the osmotic dehydration process of green beans, provided that the product has the geometric shape of an infinite cylinder. In order to examine resistance to mass flow on the surface of the product, boundary condition of the third kind was applied.

\subsubsection{The Diffusion Equation}

The diffusion equation for the case of mass transfer problems such as osmotic dehydration is given by (Luikov, 1968; Crank, 1992) as:

$$
\frac{\partial \Phi}{\partial t}=\nabla \cdot(\mathrm{D} \nabla \Phi)
$$

Where $\Phi$ represents the product moisture content $(\mathrm{db})$ and the solid gain by product, as appropriate, and $D$ is the effective mass diffusivity (moisture and solid).

It is possible to consider a cylindrical solid of radius $R$ and length $L$ as an infinite cylinder if $R$ $\ll L$ (Luikov, 1968), as shown in Fig.1. In this case, mass flow towards the central axis is considered negligible. So, Eq. (1) can be expressed in cylindrical coordinates, considering only the radial flow (Silva, 2009):

$$
\frac{\partial \Phi}{\partial t}=\frac{1}{r} \frac{\partial}{\partial t}\left(r D \frac{\partial \Phi}{\partial r}\right)
$$

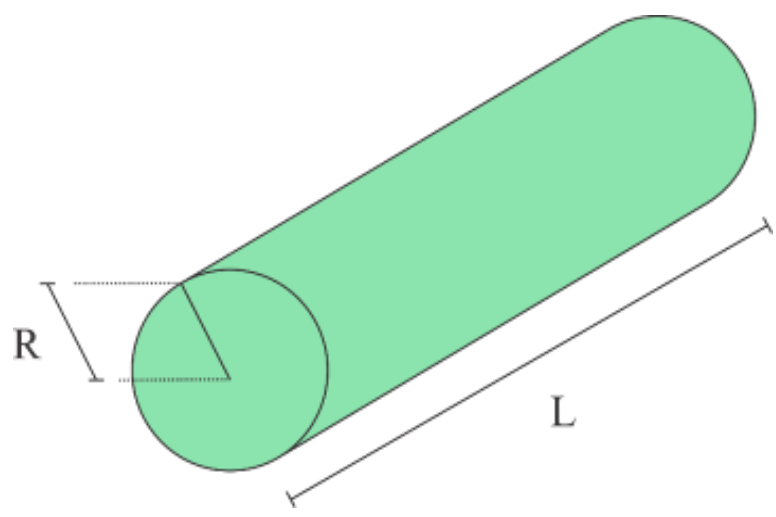

Figure 1. Cylindrical solid that can be regarded as infinite cylinder.

To solve the diffusion equation (Eq. 2) numerically and to study the mass transfer processes, the following assumptions have been considered:

- Initial distribution $\Phi$ should be uniform;

- Diffusion is the only transport mechanism inside the product; 
- The solid is considered homogeneous and isotropic;

- The convective mass transfer coefficient remains constant during the mass transfer;

- The effective mass diffusivity is assumed with a constant value.

- The diffusion process exhibits radial symmetry.

\subsubsection{Discretization of the Diffusion Equation}

Equation (2) was discretized by using the finite volume method (Patankar, 1980; Schaefer, 2006) with a fully implicit formulation. Since the radial flow is the only one considered, we have a mesh as the one shown in Fig. 2. Considering the uniform mesh and symmetry in relation to the center, a mesh is obtained as shown in Fig. 3. By integrating Eq. (2) in space ( $2 \pi r_{P} \Delta r$ ), and time ( $\left.\Delta t\right)$, we obtain the following semi-discretized equation (Eq; 3 ):

$$
\frac{\left(\lambda_{P} \Phi_{P}-\lambda_{P}^{0} \Phi_{P}^{0}\right)}{\Delta t} r_{P} \Delta r=\left.r_{e} \Gamma_{e}^{\Phi} \frac{\partial \Phi}{\partial r}\right|_{e}-\left.r_{w} \Gamma_{w}^{\Phi} \frac{\partial \Phi}{\partial r}\right|_{w}
$$

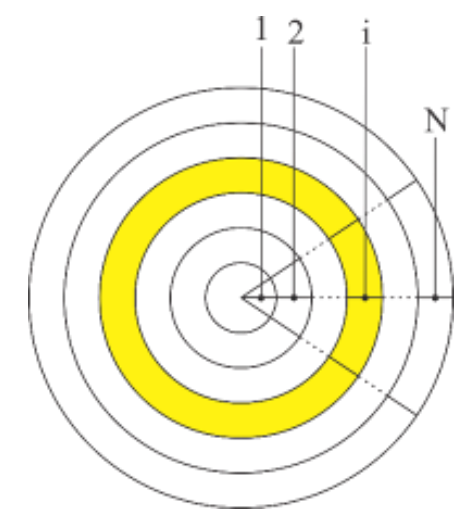

Figure 2. Infinite cylinder mesh with $\mathrm{N}$ control volumes.

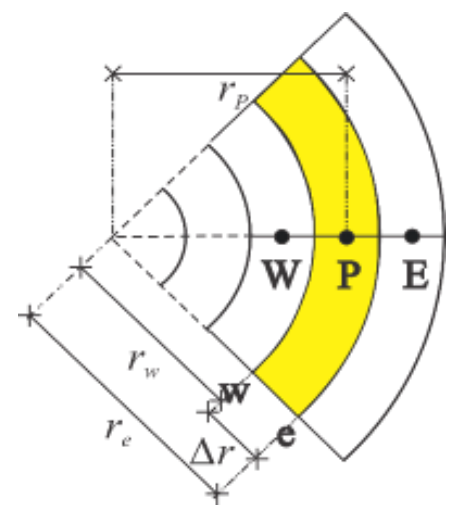

Figure 3. Mesh fragment of an infinite cylinder, taking into account its symmetry, highlighting an internal control volume and its neighbors to the west $(E)$ and to the east $(E)$. 


\section{Macrothink}

Let us now consider the following derivative approximations for the internal control volumes, i.e., the volumes that have neighbors to the east and to the west (Silva, 2009):

$$
\left.\frac{\partial \Phi}{\partial r}\right|_{e} \cong \frac{\Phi_{E}-\Phi_{P}}{\Delta r}
$$

and

$$
\left.\frac{\partial \Phi}{\partial r}\right|_{w} \cong \frac{\Phi_{P}-\Phi_{W}}{\Delta r}
$$

Thus, we obtain the following discretized equation:

$$
A_{P} \Phi_{P}=A_{e} \Phi_{E}+A_{w} \Phi_{W}+B
$$

where

$$
\begin{gathered}
A_{P}=\frac{r_{P} \Delta r}{\Delta t}+\frac{r_{e}}{\Delta r} D_{e}+\frac{r_{w}}{\Delta r} D_{w} \\
A_{w}=\frac{r_{w}}{\Delta r} D_{w} \quad A_{e}=\frac{r_{e}}{\Delta r} D_{e} \quad B=\frac{r_{P} \Delta r}{\Delta t} \Phi_{P}^{0}
\end{gathered}
$$

Where the superscript 0 of the magnitude of interest indicates that such magnitude is measured at the beginning of the time interval.

In the case of the first control volume (Fig. 4), considering the symmetry, it is assumed that $\left.\frac{\partial \Phi}{\partial r}\right|_{w}=0$. In this way, we obtain the following discretized equation (Silva, 2009):

$$
A_{P} \Phi_{P}=A_{e} \Phi_{E}+B
$$

where

$$
A_{P}=\frac{r_{P} \Delta r}{\Delta t}+\frac{r_{e}}{\Delta r} D_{e} \quad A_{e}=\frac{r_{e}}{\Delta r} D_{e} \quad B=\frac{r_{P} \Delta r}{\Delta t} \Phi_{P}^{0}
$$




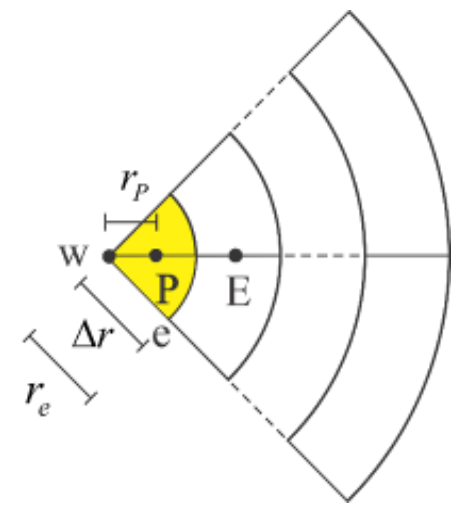

Figure 4. First control volume

The discretization of the volume control located on the border (Fig. 5) will depends on the boundary condition assumed. For boundary condition of the third kind, equality of diffusive flux from inside and convective flow from outside (solid surface) will be required. Thus:

$$
\Phi{ }_{e}=-\frac{D_{e}\left(\Phi_{e}-\Phi_{P}\right)}{\Delta r / 2}
$$

Where $\Phi{ }_{e}$ represents the magnitude of interest flow per area unit. On the other hand, the convective flow is given by

$$
\Phi_{e}=h_{e}\left(\Phi_{e}-\Phi_{\infty e}\right)
$$

Where $\Phi_{\infty e}$ is the equilibrium interest magnitude at the boundary, and $h_{e}$ is the convective mass transfer coefficient. By equating Equations (11) and (12), we find the following expression for the magnitude of interest on the east boundary:

$$
\Phi_{e}=\frac{\frac{2 D_{e}}{\Delta r}+h_{e} \Phi_{\infty e}}{\frac{2 D_{e}}{\Delta r}+h_{e}}
$$




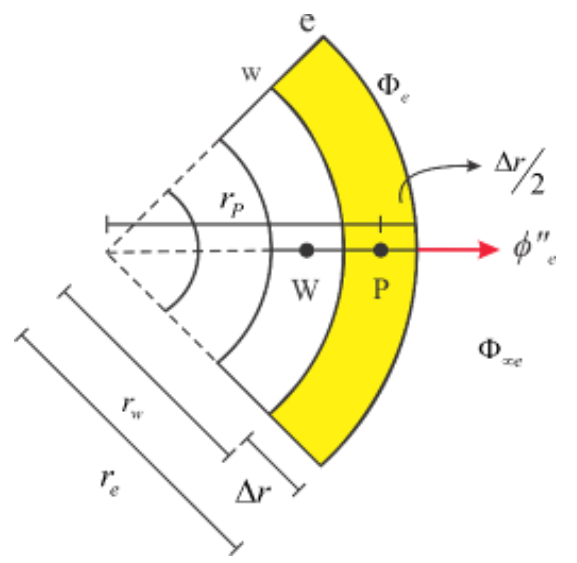

Figure 5 Volume control on the boundary of the one-dimensional mesh.

Following the appropriate substitutions and simplifications, we obtain the discretized equation for the last control volume:

$$
A_{P} \Phi_{P}=A_{w} \Phi_{W}+B
$$

Where

$$
A_{P}=\frac{r_{P} \Delta r}{\Delta t}+\frac{r_{e} D_{e}}{\frac{D_{e}}{h_{e}}+\frac{\Delta r}{2}}+\frac{r_{w} D_{w}}{\Delta r} \quad A_{w}=\frac{r_{w} D_{w}}{\Delta r} \quad B=\frac{r_{e} D_{e}}{\frac{D_{e}}{h_{e}}+\frac{\Delta r}{2}} \Phi_{\infty e}+\frac{r_{P} \Delta r}{\Delta t} \Phi_{P}^{0} .
$$

Considering $h_{e} \rightarrow \infty$, it follows that $\frac{D_{e}}{h_{e}} \rightarrow 0$. In this case, the boundary condition of the first kind is attained, permitting:

$$
A_{P}=\frac{r_{P} \Delta r}{\Delta t}+\frac{2 r_{e} D_{e}}{\Delta r}+\frac{r_{w} D_{w}}{\Delta r} \quad B=\frac{2 r_{e} D_{e}}{\Delta r} \Phi_{e}+\frac{r_{P} \Delta r}{\Delta t} \Phi_{P}^{0}
$$

For this work's simulations, effective mass diffusivity was assumed to be constant, that is: $D_{e}=D_{w}=D$. This hypothesis was assumed because shrinkage is less significant in osmotic dehydration than in drying and in this case the contanste diffusivity hypothesis is most suitable (Da Silva et al., 2012)

\subsubsection{Average value of $\Phi$}

At each time step, the numerical solution provides the value of $\Phi$ at each nodal point. As the contributions of each control volume are not the same, the average value of $\Phi$, at every time step, is calculated by using the following weighted average:

$$
\bar{\Phi}=\frac{\sum \Phi_{P} V_{P}}{\sum V_{P}}
$$


Where $V_{P}$ is the volume of each control volume.

In the literature, it is common to express the dimensionless values of $\bar{\Phi}(t)$, which are given by

$$
\bar{\Phi}^{*}(t)=\frac{\bar{\Phi}(t)-\Phi_{e q}}{\Phi_{0}-\Phi_{e q}}
$$

Where $\Phi_{0}$ represents the initial value of $\Phi$ and $\Phi_{e q}$ is the equilibrium value of $\Phi$.

\section{Validation and Convergence of Numerical Solution}

In the case of the infinite cylinder, the fully implicit formulation delivers a three-diagonal system, and, therefore, for each time step, the system obtained was resolved by the direct method: the "Three-Diagonal Matrix Algorithm" (TDMA) method. In order to validate the numerical solution, we compared it to an analytical solution. The results provided by the numerical solution were equivalent to those obtained by the analytical solution.

\subsubsection{Optimization}

In order to obtain the optimal values of the parameters $D$ and $h$, an optimizer, whose objective function is the chi-square test (Bevington and Robinson, 1992) was coupled to the numerical solution:

$$
\chi^{2}=\sum_{i=1}^{N_{P}}\left[\bar{\Phi}_{i}^{\exp }-\bar{\Phi}_{i}^{\text {sim }}(D, \mathrm{~h})\right]^{2} \frac{1}{\sigma_{i}^{2}}
$$

Where $\bar{\Phi}_{i}^{\exp }$ is the average value of $\Phi$ related to the i-th experimental point and $\bar{\Phi}_{i}^{\text {sim }}(D, \mathrm{~h})$ is the average value of $\Phi$ computed by the numerical solution as a function of $D$, and $h$. $N_{P}$ represents the number of experimental points, and $1 / \sigma^{2}$ is the statistical weight is related to $\mathrm{i}$-th experimental point. Thus, the objective function (Eq. (19)) depends on both the effective mass diffusivity and the coefficient of convective mass transfer.

\subsubsection{Experimental data of the osmotic dehydration of green bean}

The experimental data used in the simulations done for the present work were obtained by Souraki et al. (2012) concerning osmotic dehydration of green beans with initial moisture content ranging from $91 \%$ to $92 \%(\mathrm{wb}$ ), and with an average diameter of $8 \mathrm{~mm}$. The experiments were conducted in binary osmotic solutions of water and $\mathrm{NaCl}$ with nine combinations of concentrations of $10 \%, 20 \%$ and $26.5 \%$ of $\mathrm{NaCl}$ at temperatures of $30,40 \mathrm{e}$ $50^{\circ} \mathrm{C}$. The green bean to solution ratio was of $1: 20$, and the duration of the process varied from 0 to $6 \mathrm{hrs}$. In the present work, data from experiments 20 and $26.5 \%$ of $\mathrm{NaCl}$ at $50^{\circ} \mathrm{C}$ were used. More details on the experiments may be obtained from the cited reference. 


\section{Results and Discussion}

Table 1 shows the parameter values obtained from simulations for the dimensionless moisture content along the process of osmotic dehydration at concentrations of $20 \%$ and $26.5 \%$ of $\mathrm{NaCl}$ at $50{ }^{\circ} \mathrm{C}$, besides chi-square values $\chi^{2}$ and the determination coefficient $R^{2}$. Statistical weights for each experimental data were considered as 1 , because they have not been measured during the experiment implementation.

Table 1. Parameter values (SI) obtained from dimensionless simulation of moisture content under experimental conditions of $20 \%$ and $26.5 \% \mathrm{NaCl}$ at $50{ }^{\circ} \mathrm{C}$.

\begin{tabular}{|c|c|c|c|c|c|}
\hline Temperature $\left({ }^{\circ} \mathrm{C}\right)$ & Concentration $(\mathrm{NaCl})$ & $D_{w} \times 10^{10}$ & $h \times 10^{7}$ & $R^{2}$ & $\chi^{2}$ \\
\hline 50 & $20 \%$ & 2.8238 & 0.6354 & 0.9597 & $3.3456 \times 10^{-2}$ \\
\hline 50 & $26.5 \%$ & 2.2299 & 2.5207 & 0.9493 & $4.0207 \times 10^{-2}$ \\
\hline
\end{tabular}

Table 2. Values (SI) obtained from the parameters of dimensionless solids gain simulation under experimental conditions $20 \%$ and $26.5 \% \mathrm{NaCl}$ at $50{ }^{\circ} \mathrm{C}$.

\begin{tabular}{|c|c|c|c|c|c|}
\hline Temperature $\left({ }^{\circ} \mathrm{C}\right)$ & Concentration $(\mathrm{NaCl})$ & $D_{s} \times 10^{10}$ & $h \times 10^{6}$ & $R^{2}$ & $\chi^{2}$ \\
\hline 50 & $20 \%$ & 1.4774 & 1.7749 & 0.9483 & $3.9995 \times 10^{-2}$ \\
\hline 50 & $26.5 \%$ & 1.7099 & 2.2314 & 0.9772 & $1.7521 \times 10^{-2}$ \\
\hline
\end{tabular}

For water, the convective mass transfer coefficient, $h$, shown in Table 1 indicates that $h \rightarrow \infty$, suggesting that first kind boundary condition is most appropriate. It may also be noticed a decrease in the water effective diffusivity when the concentration varies from 20 to $26.5 \%$. Such phenomenon was observed by Singh et al. (2008) during the process of osmotic dehydration of carrot cubes in $\mathrm{NaCl}$ solutions. The authors explained the phenomenon by explaining that the salt impregnated in the product during drying makes it difficult for the water to flow out of the product. The values obtained for effective diffusivity of water are in agreement with the values found in the literature (Derrossi et al, 2008; Mundada et al, 2011; Uribe et al, 2011).

Figure 6 exhibits the fitting of numerical solution to the experimental data. Table 2 exhibits the parameter values obtained from simulations of dimensionless gain of solids in the osmotic dehydration process at concentrations of $20 \%$ and $26.5 \% \mathrm{NaCl}$ at $50{ }^{\circ} \mathrm{C}$. The values of coefficient of convective mass transfer shown in Table 2 indicate that - unlike the water flow where the product surface offers no resistance - resistance to the flow of solids is found. Consequently, the boundary condition of the third kind is more appropriate for this problem, since this type of condition enables us to analyze the two cases that have been observed. This possibility of to analyze the two cases shows an advantage of the proposed model compared to 


\section{Macrothink}

those found in the literature. Furthermore, the values of the physical parameters were shown to be consistent, since the solution concentration influences both the effective diffusivity of solids and the coefficient of convective mass transfer. It has also been observed that the values found for the effective diffusivity of water were higher than the values for effective diffusivity of solids. This phenomenon can be explained by the fact that salt molecules are higher than water molecules, so the product offers more resistance to the incorporation of solids than to water loss (Fernandes et al, 2006; Fernandes et al, 2009; Mundada et al., 2011). Figure 7 exhibits fitting of numerical solution to the experimental data.

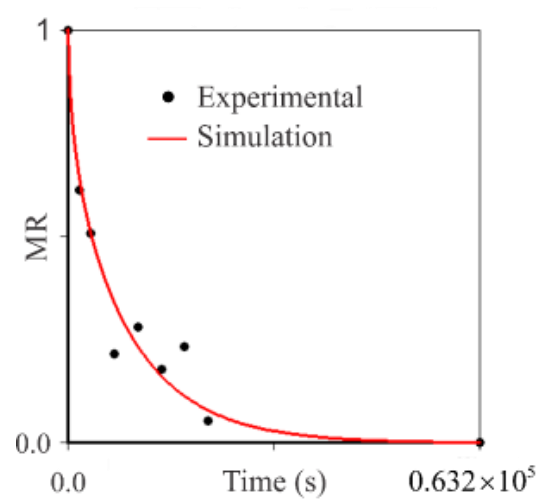

(a)

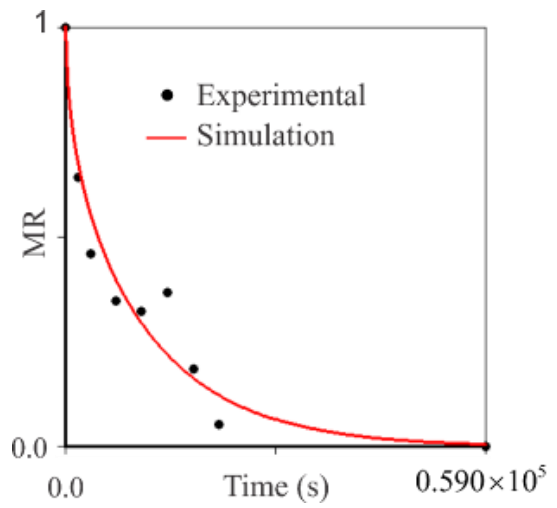

(b)

Figure 6. Adjustment of numerical solution to the moisture content experimental data under experimental conditions (a) $20 \% \mathrm{NaCl}$ and $50{ }^{\circ} \mathrm{C}$, (b) $26.5 \% \mathrm{NaCl}$ and $50^{\circ} \mathrm{C}$.

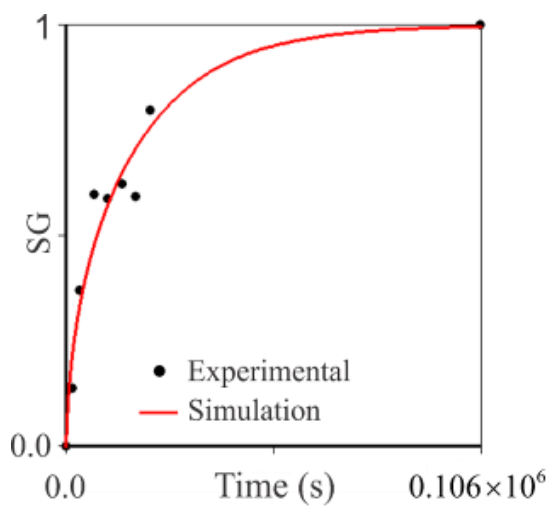

(a)

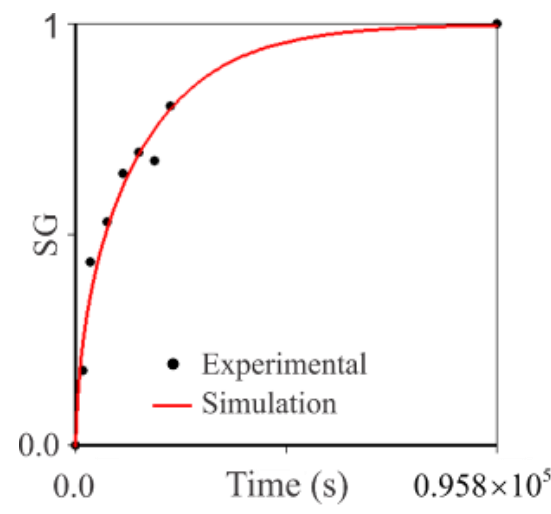

(b)

Figure 7. Numerical solution adjustment to the experimental data of solids gains under experimental conditions (a) $20 \% \mathrm{NaCl}$ and $50^{\circ} \mathrm{C}$, (b) $26.5 \% \mathrm{NaCl}, 50^{\circ} \mathrm{C}$. 


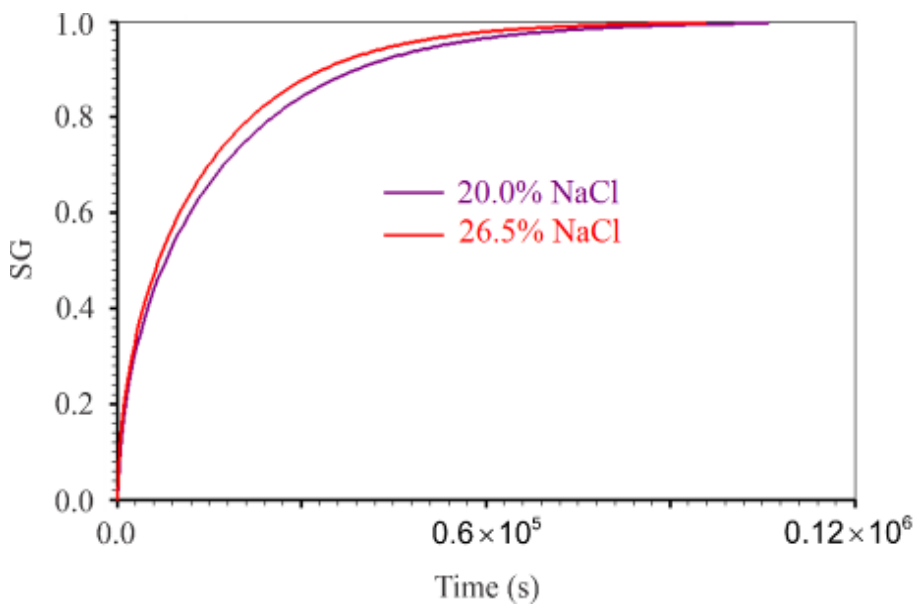

Figure 8. Superposition of numerical solutions to concentrations of $20 \%$ and $26.5 \% \mathrm{NaCl}$.

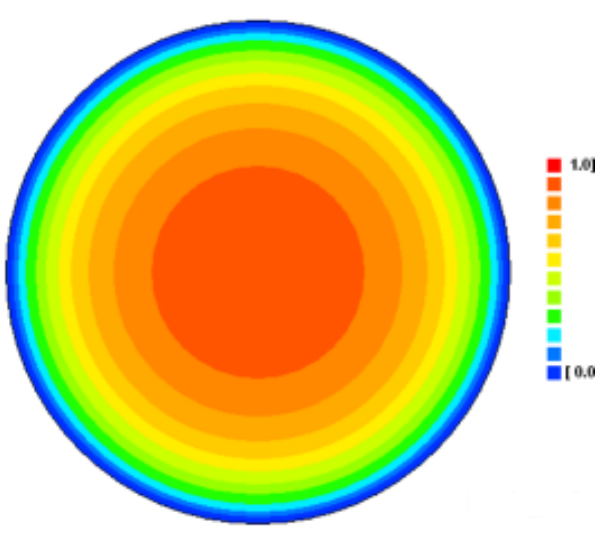

(a)

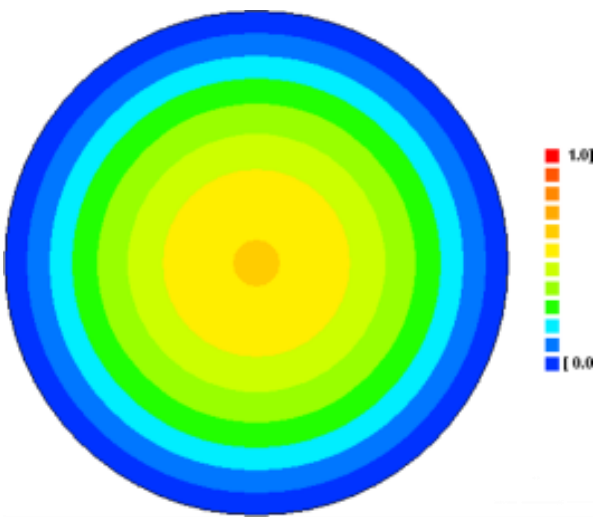

(b) 


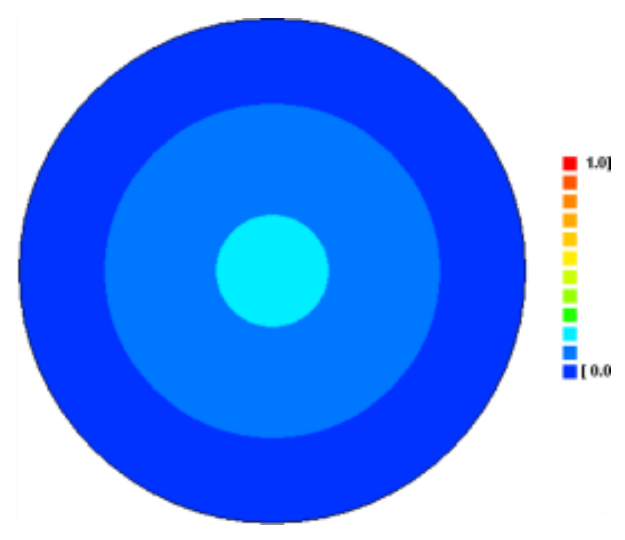

(c)

Figure 9. Distribution of moisture in osmotic dehydration at concentrations of $20 \% \mathrm{NaCl}$ and $50{ }^{\circ} \mathrm{C}$, at time steps t: (a) $0.3600 \times 10^{4} \mathrm{~s}$; (b) $0.1080 \times 10^{5} \mathrm{~s}$; (c) $0.2520 \times 10^{5} \mathrm{~s}$.

Figure 8 shows superposition of simulations for concentrations of $20 \%$ and $26.5 \%$ of $\mathrm{NaCl}$. One can also notice the concentration influence on the incorporation of solids. In a concentration of $26.5 \%$, as expected, the simulation presents a much greater assimilation.

One of the greatest advantages of diffusion models is the possibility of simulating the distribution of moisture and solids within the product over processing time. In Fig. 9 moisture distribution in the product for the instants 3600, 10800 and $25200 \mathrm{~s}$ is displayed after the osmotic dehydration initiation in solution of $20 \% \mathrm{NaCl}$ at a temperature of $50^{\circ} \mathrm{C}$. At the same time, Fig. 10 shows the moisture distribution in the product at concentrations of $26.5 \% \mathrm{NaCl}$ at the same temperature for the same time instants at concentration of $20 \%$.

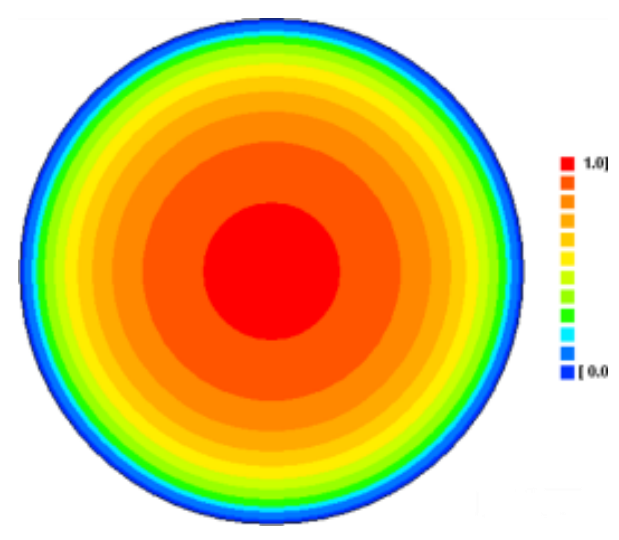

(a) 


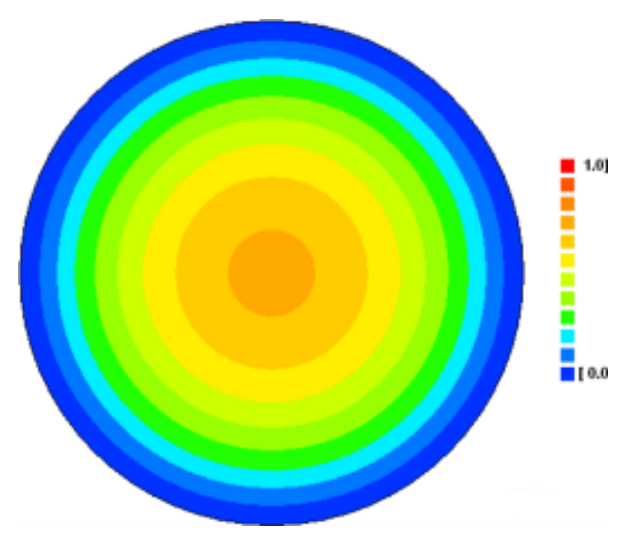

(b)

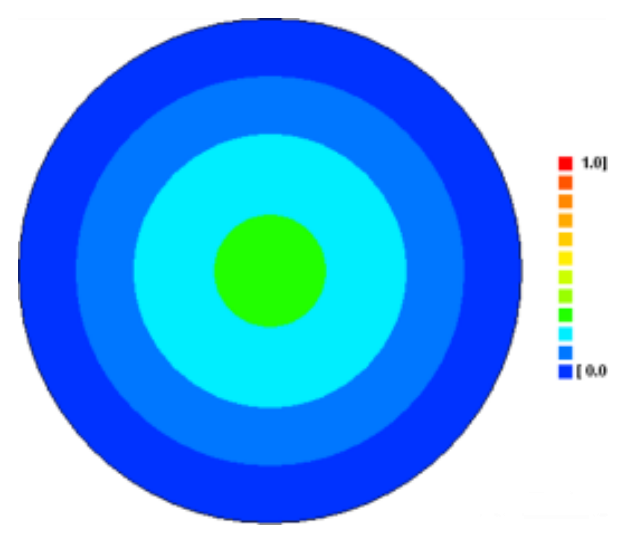

(c)

Figure 10. Distribution in moisture to osmotic dehydration in concentrations of $26.5 \% \mathrm{NaCl}$ and $50{ }^{\circ} \mathrm{C}$, at time steps t: (a) $0.3600 \times 10^{4} \mathrm{~s}$; (b) $0.1080 \times 10^{5} \mathrm{~s}$; (c) $0.2520 \times 10^{5} \mathrm{~s}$.

In Figs. 9 (a) and 10 (a) we can see that - at the very first hour of the process - the region next to border takes over the equilibrium value of magnitude. This highlights boundary conditions of the first kind. Furthermore, overall equilibrium is almost reached after about 6 hours for the concentration of $20 \% \mathrm{NaCl}$. Moreover, it was previously observed that diffusivity presented a slight decrease in concentrations of $20 \%$ up to $26.5 \% \mathrm{NaCl}$. This can be explained by the amount of salt impregnated in the product. By comparing Figures 9 and 10 one can easily see that such phenomenon is most noticeable especially when the core of the product is examined. In Fig. 9 (c) the core of the product is found to be in equilibrium, whereas in Fig. 10 (c) the core of the product has not yet reached equilibrium. 


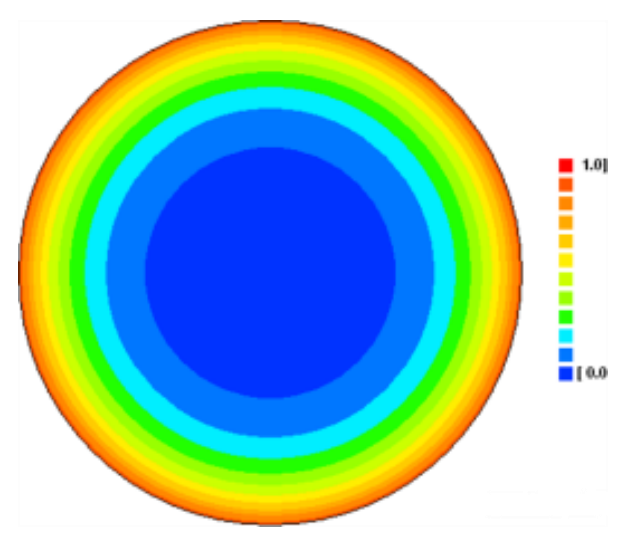

(a)

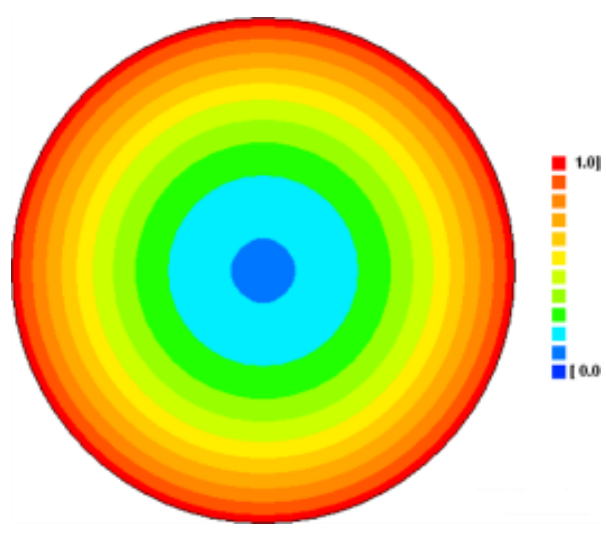

(b)

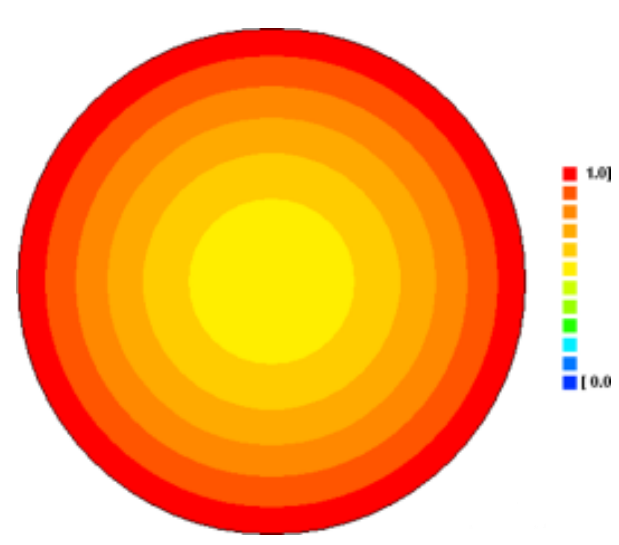

(c)

Figure 11. Distribution of solids in osmotic dehydration at concentrations of $20 \% \mathrm{NaCl}$ and $50{ }^{\circ} \mathrm{C}$, at time t: (a) $0.3600 \times 10^{4} \mathrm{~s}$; (b) $0.1080 \times 10^{5} \mathrm{~s}$; (c) $0.2520 \times 10^{5} \mathrm{~s}$.

About to the solute transport, Figs. 11 and 12 show the distribution of solids for process of osmotic dehydration at $50{ }^{\circ} \mathrm{C}$ for concentrations of $20 \%$ and $26.5 \% \mathrm{NaCl}$, respectively. The instants of time 3600,10800 and $25200 \mathrm{~s}$ are analyzed. Figure 11(a) shows that after 1 hour of the process, the border has not yet reached the desired equilibrium. Accordingly, the boundary condition of the third type becomes evident. The border starts to reach equilibrium 3 hours later, 
which shows the product surface resistance to solid flow. The border presents no resistance to water flow.

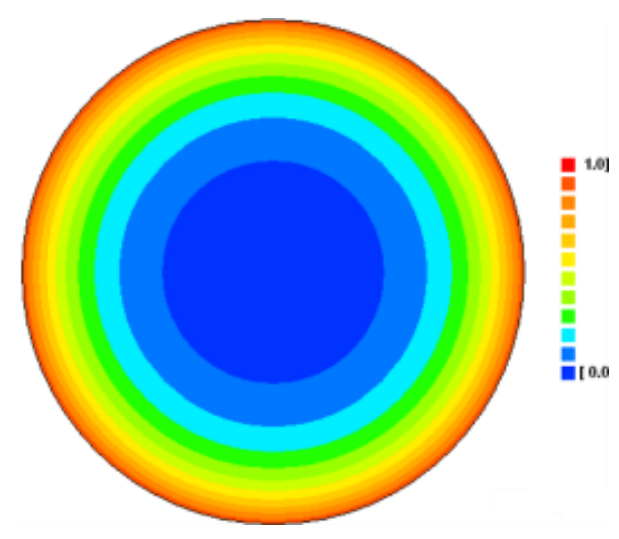

(a)

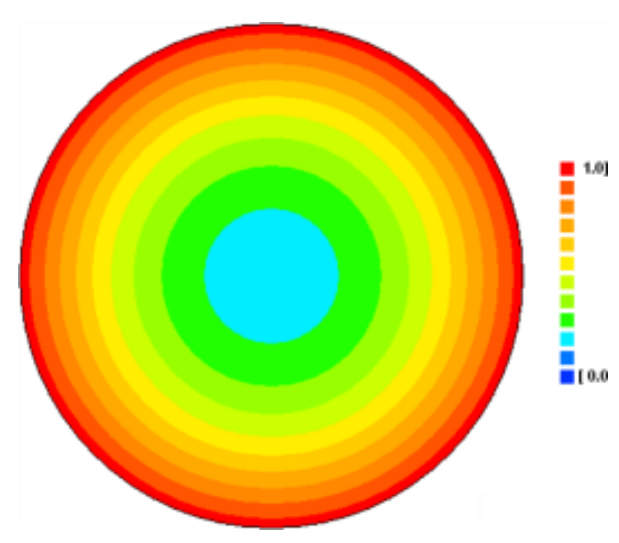

(b)

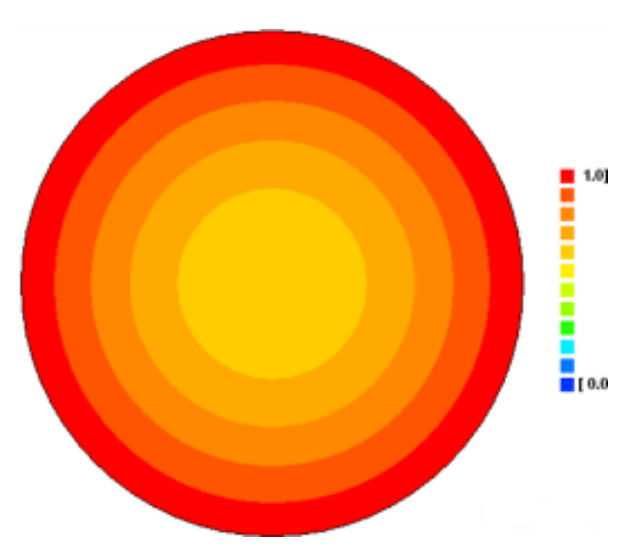

(c)

Figure 12. Distribution of solids in osmotic dehydration in concentrations of $26.5 \% \mathrm{NaCl}$ and $50{ }^{\circ} \mathrm{C}$, at time t: (a) $0.3600 \times 10^{4} \mathrm{~s}$; (b) $0.1080 \times 10^{5} \mathrm{~s}$; (c) $0.2520 \times 10^{5} \mathrm{~s}$.

By comparing Figs. 11(a) and 12(a), one can find the expected result: the concentration of $\mathrm{NaCl}$ as having influenced the incorporation of solids. In other words the higher the 
concentration, the faster is the incorporation of solids. The same can be observed of Figs. 11(b) and 12(b). In the simulation of various processes of osmotic dehydration, shrinkage cannot be neglected. By considering shrinkage, one cannot fail to admit the variation of effective diffusivity (Silva et al., 2014). In this case, the numerical solution developed in this work can be used to approach this question. Additionally, the parameter values obtained may be used as initial values for the optimization process.

\section{Conclusions}

The osmotic dehydration process of green beans has been studied by using a diffusion model. A numerical solution to the diffusion equation in cylindrical coordinates has been proposed. By analyzing the results obtained via numerical solution, it has been concluded that the model used is suitable for the description of the problem. This model has allowed us to conclude that the product surface exerts a resistance to the flow of solids, but it offers no resistance to water flow. It has also been observed that the coefficient of convective mass transfer (water) presented higher values. Consequently, a boundary condition of the first kind may be considered. Regarding solid gains, the coefficient of convective mass transfer (solids) presented resistance to the incorporation of solids. As a result, boundary condition of the third kind is most suitable, and thus the proposed model presents an advantage over those found in the literature. It has been observed a decrease in the effective diffusivity of water by increasing its concentration, which reveals that salt impregnation in the product caused resistance to water flow. This phenomenon has also been observed by other researchers. A better approach to this problem includes the introduction of product shrinkage and the variation of parameters to the model described in this article. Therefore, further studies are needed considering this type of modeling.

\section{Acknowledgment}

The authors thank CNPq (Conselho Nacional de Desenvolvimento Científico e Tecnológico) for the support given to this research in accordance with research grant (Process Number 301697/2012-4).

\section{References}

Azuara, E., Flores, R., Garcia, H. S., Beristain, C. I., (1992), "Kinect model for osmotic dehydration and its relationship with Fick's second law", International Journal of Food Science and Technology, 27, 409-418. http://dx.doi.org/10.1111/j.1365-2621.1992.tb01206.x

Bevington, P. R., Robinson, D, K., (1992). "Data reduction and error analysis for the Physical Sciences". Second ed., WCB/McGraw-Hill, Boston.

Crank, J., (1992). The Mathematics of Diffusion, Clarendon Press, Oxford, UK.

Da Silva, W. P., Silva, C. M. D. P. S., Farias, V. S. O., \& Gomes, J. P. (2012). Diffusion models to describe the drying process of peeled bananas: optimization and simulation. Drying Technology, 30, 164-174. http://dx.doi.org/10.1080/07373937.2011.628554

Derossi, A., Pilli, T. De, Severini, C., McCarthy, M. J., (2008,). Mass transfer during osmotic 
dehydration of apples, Journal of Food Engineering, 86, 519-528. http://dx.doi.org/10.1016/j.jfoodeng.2007.11.007

Doymaz, I., (2005). Drying behaviour of green beans, Journal of Food Engineering, 69, 161-165. http://dx.doi.org/10.1016/j.jfoodeng.2004.08.009

Doymaz, I., Ismail, O., (2011). Drying characteristics of sweet cherry, Food and Bioproducts Processing, 89, 31-38. http://dx.doi.org/10.1016/j.fbp.2010.03.006

Falade, K. O., Igbeka, J. C., Ayanwuyi, F. A., (2007). Kinetics of mass transfer, and colour changes during osmotic dehydration of watermelon, Journal of Food Engineering, 80, 979-985. http://dx.doi.org/10.1016/j.jfoodeng.2006.06.033

Fante, C., Corrêa, J., Natividade, M., Lima, J., Lima, L., (2011). Drying of plums (Prunus sp, c.v Gulfblaze) treated with $\mathrm{KCl}$ in the field and subjected to pulsed vacuum osmotic dehydration, International Journal of Food Science and Technology, 46. 1080-1085. http://dx.doi.org/10.1111/j.1365-2621.2011.02619.x

Fathi, M., Mohebbi, M., Razavi, S. M. A., (2011). Application of Image Analysis and Artificial Neural Network to Predict Mass Transfer Kinetics and Color Changes of Osmotically Dehydrated Kiwifruit, Food Bioprocess Technology, 04, 1357-1366. http://dx.doi.org/10.1007/s11947-009-0222-y

Fernandes, F. A. N., Gallão, M. I., Rodrigues, S., (2009,). Effect of osmosis and ultrasound on pineapple cell tissue structure during dehydration, Journal of Food Engineering, 90, 186-190. http://dx.doi.org/10.1016/j.jfoodeng.2008.06.021

Fernandes, F. A. N., Gallão, M. I., Rodrigues, S., Gaspareto, O. C. P., Oliveira, E. L., (2006). Optimization of osmotic dehydration of bananas followed by air-drying, Journal of Food Engineering, 77, 188-193. http://dx.doi.org/10.1016/j.jfoodeng.2005.05.058

Kaleta, A., Górnicki, K., (2010). Evaluation of drying models of apple (var. McIntosh) dried in a convective dryer, International Journal of Food Science and Technology, 45, 891-898. http://dx.doi.org/10.1111/j.1365-2621.2010.02230.x

LUIKOV, A. V. “Analytical heat diffusion theory”. Academic Press, Inc. Ltd: London, 1968, $685 \mathrm{p}$.

Mercali, G. D., Marczak, L. D. F., Tessaro, I. C., Noreña, C. P. Z., (2011). Evaluation of water, sucrose and $\mathrm{NaCl}$ effective diffusivities during osmotic dehydration of banana (Musa sapientum, shum.), LWT - Food Science and Technology, 44, 82-91. http://dx.doi.org/10.1016/j.lwt.2010.06.011

Mundada, M., Hathan, B. S., Maske, S., (2011). Mass Transfer Kinetics during Osmotic Dehydration of Pomegranate Arils, Journal of Food Science, 75, 31-39. http://dx.doi.org/10.1111/j.1750-3841.2010.01921.x

Patankar, S. V., (1980). Numerical heat transfer and fluid flow, New York: Hemisphere Publishing Corporation. 
Porciuncula, B. D. A., Zotarelli, M. Z., Carciofi, B. A. M., (2013). Determining the effective diffusion coefficient of water in banana (Prata variety) during osmotic dehydration and its use in predictive models, Journal of Food Engineering, 119, 490-496. http://dx.doi.org/10.1016/j.jfoodeng.2013.06.011

Ruiz-López, I. I., Castillo-Zamudio, R. I., Salgado-Cervantes, M. A., Rodríguez-Jimenes, G. C., García-Alvarado, M. A., (2010). Mass transfer modeling during osmotic dehydration of hexahedral pineapple slices in limited volume solutions, Food and Bioprocess Technology. 3, 427-433. http://dx.doi.org/10.1007/s11947-008-0102-x

Schäfer, M., (2006). Computational Engineering -Introduction to Numerical Methods, Springer, Berlin.

Silva, W. P. Discretizações em fenômenos de transporte computacional, Cursos 1 e 2 (2009) Apresentações em Powerpoint, online, disponível no endereço eletrônico: <http://zeus.df.ufcg.edu.br/labfit/TCMFC.htm>, data de acesso: 13/11/2013.

Silva, W. P., Silva C., M. D. P. S., Silva D., D. P. S., Neves, G. A., Lima, A. G. B., (2010). Mass and heat transfer study in solids of revolution via numerical simulations using finite volume method and generalized coordinates for the Cauchy boundary condition, International Journal of Heat and Mass Transfer, 53, 1183-1194. http://dx.doi.org/10.1016/j.ijheatmasstransfer.2009.10.028

Silva, W. P., Silva C., M. D. P. S., Gama, F. J. A., Gomes, J. P., (2013a). Mathematical models to describe thin-layer drying and to determine drying rate of whole bananas, Journal of the Saudi Society of Agricultural Sciences. http://dx.doi.org/10.1016/j.jssas.2013.01.003

Silva, W. P., Silva C., M. D. P. S., Aires, J. E. F., Junior, A. F. S., (2013b). Osmotic dehydration and convective drying of coconut slices: Experimental determination and description using one-dimensional diffusion model", Journal of the Saudi Society of Agricultural Sciences. http://dx.doi.org/10.1016/j.jssas.2013.05.002

Silva, W. P., Amaral, D. S., Duarte, M. E. M, Mata, M. E. R. M. C., Silva C., M. D. P. S., Pinheiro, R. M. M., Pessoa, T., (2013c). Description of the osmotic dehydration and convective drying of coconut (Cocos nucifera L.) pieces: A three-dimensional approach, Journal of Food Engineering, 115, 121-131. http://dx.doi.org/10.1016/j.jfoodeng.2012.10.007

Silva, W. P., Silva C., M. D. P. S., Gomes, J. P., (2013d). Drying description of cylindrical pieces of bananas in different temperatures using diffusion models, Journal of Food Engineering, 117, 417-424. http://dx.doi.org/10.1016/j.jfoodeng.2013.03.030

Silva, W. P., Silva C., M. D. P. S., Lins, M. A. A., (2014). Osmotic dehydration of pineapple (Ananas comosus) pieces in cubical shape described by diffusion models, LWT - Food Science and Technology, 55, 1-8. http://dx.doi.org/10.1016/j.lwt.2013.08.016

Singh, B., Panesar, P. S., Nanda, V., (2008), Osmotic dehydration kinetics of carrot cubes in sodium chloride solution, International Journal of Food Science and Technology, 43, 1361-1370. http://dx.doi.org/10.1111/j.1365-2621.2007.01623.x 


\section{Al Macrothink}

Journal of Agricultural Studies

ISSN 2166-0379 2015, Vol. 3, No. 1

Souraki, B. A., Ghaffari, A., Bayat, Y., (2012). Mathematical modeling of moisture and solute diffusion in the cylindrical green bean during osmotic dehydration in salt solution, Food and Bioproducts Processing, 90, 64-71. http://dx.doi.org/10.1016/j.fbp.2010.11.015

Souraki, B. A., Ghavami, M., Tondro, H., (2013). Mass transfer during osmotic dehydration of green bean in salt solution: A polynomial approximation approach, Food and Bioproducts Processing, 91, 257-263. http://dx.doi.org/10.1016/j.fbp.2012.11.002

Sutar, P. P., Raghavan, G. V. S., Gariepy, Y., Prasad, S., Trivedi, A., (2012). Optimization of osmotic dehydration of potato cubes under pulsed microwave vacuum environment in ternary solution, Drying Technology, 30 , 1449-1456. http://dx.doi.org/10.1080/07373937.2012.688909

Uribe, E., Miranda, M., Vega-Gálvez, A., Quispe, I., Clavería, R., Di Scala, K., (2011). Mass transfer modelling during osmotic dehydration of jumbo squid (Dosidicus gigas): influence of temperature on diffusion coefficients and kinetic parameters, Food Bioprocess Technology, 04, 320-326. http://dx.doi.org/10.1007/s11947-010-0336-2

\section{Copyright Disclaimer}

Copyright for this article is retained by the author(s), with first publication rights granted to the journal.

This is an open-access article distributed under the terms and conditions of the Creative Commons Attribution license (http://creativecommons.org/licenses/by/3.0/). 